\title{
THE APRIL MEETING IN BERKELEY
}

The three hundred sixty-seventh meeting of the American Mathematical Society was held at the University of California, Berkeley, California, on Saturday, April 6, 1940. The attendance was about eighty including the following forty-one members of the Society:

H. M. Bacon, G. A. Baker, Clifford Bell, B. A. Bernstein, H. F. Blichfeldt, J. L. Brenner, D. G. Chapman, C. L. Clark, P. H. Daus, L. E. Dickson, F. W. Dresch, G. C. Evans, A. L. Foster, E. C. Goldsworthy, E. R. Hedrick, A. E. Ingham, C. G. Jaeger, S. H. Levy, Hans Lewy, A. E. Marston, C. B. Morrey, F. R. Morris, Jerzy Neyman, A. R. Noble, C. A. Noble, C. D. Olds, W. G. Palm, W. T. Puckett, T. M. Putnam, S. E. Rauch, R. M. Robinson, E. B. Roessler, A. C. Schaeffer, W. H. Simons, Gabor Szegö, A. E. Taylor, J. V. Uspensky, F. A. Valentine, W. F. Whitmore, A. R. Williams, O. V. Wood.

General sessions were held both Saturday morning and afternoon. Professors Hedrick, Szegö and Blichfeldt presided over the meeting at various times. The following resolution was passed during the morning session :

"Those in attendance at this meeting of the American Mathematical Society wish to go on record as favoring that a program of mathematics be provided in the secondary schools, beginning normally with algebra in the ninth year, to be available for those who wish to elect it or who otherwise need it in preparation for college work.

"It is felt that a capable student should be able to secure solid geometry and trigonometry in the secondary school."

The titles and cross references to abstracts of papers read at the meeting are given below. Papers whose abstract numbers are followed by the letter $t$ were read by title. Professor A. G. Clark and Mr. G. B. Dantzig were introduced by Professor Jerzy Neyman, Mr. J. R. Woolson, Mr. S. P. Avann, Mr. J. P. LaSalle, and Mr. A. B. Mewborn by Professor A. D. Michal, and Mr. R. W. Shephard and Mr. Lewis Nelson by Professor G. C. Evans.

1. J. L. Brenner: Well-orderable abelian groups whose elements have prime-power order. (Abstract 46-5-240.)

2. P. H. Daus: Bisecting circles. (Abstract 46-5-256.)

3. B. A. Bernstein: Groups in terms of addition and negation. (Abstract 46-5-236.)

4. C. D. Olds: On the number of representations of the square of an integer as the sum of an odd number of squares. (Abstract 46-5-309.)

5. G. B. Dantzig: On the non-existence of tests of "Student's" hypothesis, the power function of which would be independent of $\sigma$. (Abstract 46-5-255.) 
6. F. W. Dresch: A mathematical model of a dynamic economic system. (Abstract 46-5-263.)

7. J. R. Woolson: The mean of the iteration of linear operators in reflexive Banach spaces. Preliminary report. (Abstract 46-5-351.)

8. A. C. Schaeffer and Gabor Szegö: Inequalities for harmonic polynomials in two and three dimensions. (Abstract 46-5-321.)

9. Lewis Nelson: An Abel integral equation with constant limits of integration. (Abstract 46-5-305.)

10. A. R. Williams: On a certain Cremona transformation between two $(n-1)$-spaces in $S_{n}$. (Abstract 46-5-350.)

11. W. T. Puckett: On arc-preserving transformations. (Abstract 46-5-316.)

12. R. W. Shephard: The length of production and related dynamic aspects of a simplified economic system. Preliminary report. (Abstract 46-5-323.)

13. S. P. Avann: Lattice automorphisms. (Abstract 46-5-227-t.)

14. J. P. LaSalle: Applications of the pseudo-norm to the study of linear topological spaces. (Abstract 46-5-290-t.)

15. A. D. Michal and Max Wyman: Characterization of complex couple spaces. (Abstract 46-5-299-t.)

16. G. B. Dantzig: Existence of the Neyman-Pearson unbiased test of Type A. (Abstract 46-5-254-t.)

17. A. B. Mewborn: Abstract local geometry of paths. II. (Abstract 46-5-297-t.)

18. E. T. Bell: Note on a certain type of diophantine system. (Abstract 46-5-233-t.)

19. E. T. Bell: Postulational basis for the umbral calculus. (Abstract 46-5-234-t.)

20. A. G. Clark: Two sample problem concerning Poisson and binomial distributions. Preliminary report. (Abstract 46-5-249-t.)

T. M. Putnam, Associate Secretary 